Article

\title{
Partial Least Squares Regression Approach in the Analysis of Damage Intensity Changes to Prefabricated RC Buildings during the Long Term of Mining Activity
}

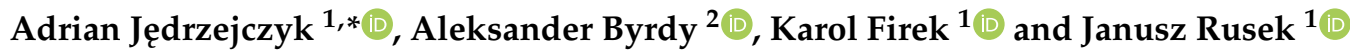 \\ 1 Faculty of Mining Surveying and Environmental Engineering, AGH University of Science and Technology, \\ al. Mickiewicza 30, 30-059 Cracow, Poland; kfirek@agh.edu.pl (K.F.); rusek@agh.edu.pl (J.R.) \\ 2 Faculty of Civil Engineering, Cracow University of Technology, ul. Warszawska 24, 31-155 Cracow, Poland; \\ abyrdy@pk.edu.pl \\ * Correspondence: jedrzejczyk@agh.edu.pl
}

check for

updates

Citation: Jędrzejczyk, A.; Byrdy, A.; Firek, K.; Rusek, J. Partial Least Squares Regression Approach in the Analysis of Damage Intensity Changes to Prefabricated RC Buildings during the Long Term of Mining Activity. Appl. Sci. 2022, 12, 467. https://doi.org/10.3390/ app12010467

Academic Editors: Humberto Varum and José Melo

Received: 8 December 2021

Accepted: 2 January 2022

Published: 4 January 2022

Publisher's Note: MDPI stays neutral with regard to jurisdictional claims in published maps and institutional affiliations.

Copyright: (C) 2022 by the authors. Licensee MDPI, Basel, Switzerland. This article is an open access article distributed under the terms and conditions of the Creative Commons Attribution (CC BY) license (https:// creativecommons.org/licenses/by/ $4.0 /)$.

\begin{abstract}
This article presents the results of the analysis of the extent of damage to 138 multi-storey buildings with reinforced concrete prefabricated structure, which are located in the mining terrain of the Legnica-Głogów Copper District. These objects are residential and public utility buildings of up to 43 years old, erected in industrialized prefabricated technologies: large-block and large-panel systems. The research was based on the results of technical condition inventory carried out in 2002, 2007 and 2012. As part of the analysis, the damage intensity index $w_{u}$ was established for individual structural and finishing elements of the studied buildings. This index is defined on a six-point scale, which includes a detailed description of the extent of damage that corresponds to the successive degrees of intensity. As part of the research, the databases were significantly expanded and the generalized formulas of the damage intensity index $w_{u}$ for individual groups of buildings were verified. For this purpose, the partial least squares regression (PLSR) method was applied. Thereafter, the analysis of changes of this intensity in time was carried out and the relations between the extent of damage and the impacts of mining exploitation were examined. The approach presented in this paper and obtained research results are characterized by a high degree of utilitarianism and can be applied to increase the efficiency in the optimal maintenance management of buildings, including planning of repairs and retrofits throughout the technical life cycle of the buildings.
\end{abstract}

Keywords: partial least squares regression; building damage; technical condition; reinforced concrete prefabricated building structures; mining impacts; sustainable development

\section{Introduction}

The idea of sustainable development is a multidimensional concept that emphasizes the integration and achievement of a dynamic balance between economic, social and environmental aspects [1]. One of the fundamental assumptions of this doctrine is to achieve social balance by, among others, increasing the economic and environmental efficiency of planned building development projects. In recent years, there has been an intensive growth of issues in the field of sustainable development. This includes the field of civil engineering and its branch in the form of building engineering [2-4]. Sustainability, in addition to improving building materials to be used in recently erected buildings, also extends to existing structures. An important factor leading to the development of existing buildings is the consideration of the often-negative impacts of the external environment impacts. Environmental impacts include earthquakes induced by geogenic (e.g., tectonic plate movements) [5] as well as those with anthropogenic origins (e.g., underground mining).

Underground mining interferes with the rock mass and leads to the formation of stresses and strains inside the rock mass, which may result in the occurrence of deformations on the ground surface and mining tremors which, in turn, may have an adverse effect on 
building structures [6-9]. During the inventory of the technical condition of buildings in mining terrain, special attention should be paid to the assessment of the extent and intensity of damage, especially in the context of determining the causes of their formation as well as ways of their repair $[10,11]$. Correct assessment of the technical condition is the basis for maintenance management of the building, in particular, planning and determining the scope of future repair works [12-14].

Damage to building structures is generally considered according to two criteria: safety and serviceability. They are the basis at the design stage and are verified during the technical life cycle of buildings. However, nowadays, with the development of the idea of energy-efficient construction and reductions in $\mathrm{CO} 2$ emissions into the atmosphere, the range of requirements for buildings has been extended to include demands for energy consumption and durability. All this is included in the idea of sustainable development in buildings industry $[15,16]$. Currently, the result of such efforts is a transformation of the so far binding safety and serviceability criteria, which is to include also socio-economic and environmental aspects [17]. As a result, the range of necessary conditions to be fulfilled is considerably extended, forcing the use of multiple-criteria decision-making (MCDM) methods in the design process $[18,19]$.

From the technical and social point of view, multifamily residential and public utility buildings erected in large-block and large-panel systems are a particularly important group of buildings [20]. This also includes mining areas. In works [21-24], a proposal was presented for a universal classification of damage intensity of particular elements of buildings, both of masonry construction, prefabricated building structures, and skeleton objects. Then, on the basis of this classification, the methodology (in the field of data mining) was established for determining generalized damage intensity indices for particular types of buildings.

The aim of the research presented in this paper was to verify the generalized formulas of the damage intensity index $w_{u}$ of large-block and large-panel buildings as a linear combination of $w_{u i}$ indices describing damage to its components (structural and secondary) based on extended databases. Another purpose was analysis of changes in the intensity of damage to them in time and examination of relations between the extent of damage and the impact of mining exploitation.

The research was based on the database on the construction, technical condition and potential causes of damage of 64 buildings erected in the large-block system and 74 buildings erected in the large-panel system, located in the Legnica-Głogów Copper District (LGCD). Over the entire period of their lifetime, these buildings have been subjected to mining impacts in the form of surface deformation and rock mass tremors. For these buildings, 22 indices describing the damage of all their structural and secondary elements were initially specified [21,22]. Taking into account a relatively large number of variables (22 damage intensity indices $w_{u i}$ ) and statistically significant mutual correlations between some of the indicators, it was found that there is a need for preliminary assessment and selection of variables for the purpose of establishing linear models of the damage intensity index in the analysed groups of buildings.

\section{Materials and Methods}

\subsection{Methodology of the Research}

The partial least squares regression (PLSR) method, based on the results of the NIPALS (nonlinear partial least squares) iterative algorithm [25-29], was used to determine the damage intensity index of large-block and large-panel buildings.

Basically, the PLSR method can be divided into two simultaneous procedures [25]. The first involves identification of the principal components in the input variable space, and the second the relationships binding these components with the dependent variable. As part of this study, the PLSR method was used at the level of individual principal components and their subsequent verification. Such a course of action allows finding one of the most efficient linear combinations between input variables. 
The PLSR method assumes that both the variables from the input space $\mathbf{X}$ and output space $\mathbf{Y}$ can be written as the sum of the linear combinations of the vectors $\mathbf{t}$ and $\mathbf{p}$ as well as $\mathbf{q}$ and $\mathbf{u}$, i.e., the scores and loadings. These relationships have the following form [26]:

$$
\begin{gathered}
\mathbf{X}=\sum_{i=1}^{a} \mathbf{t}_{i} \mathbf{p}_{i}=\mathbf{T} \mathbf{P}^{T} \\
\mathbf{Y}=\sum_{i=1}^{a} \mathbf{q}_{i} \mathbf{u}_{i}=\mathbf{Q} \mathbf{U}^{T}
\end{gathered}
$$

where:

$\mathbf{X}=\left\{\mathbf{x}_{1}, \mathbf{x}_{2}, \ldots, \mathbf{x}_{i}, \ldots, \mathbf{x}_{m}\right\}$ 一the input variable space,

$\mathbf{Y}=\left\{\mathbf{y}_{1}, \mathbf{y}_{2}, \ldots, \mathbf{y}_{i}, \ldots, \mathbf{y}_{m}\right\}$-the output variable space,

$a$-arbitrarily determined number of principal components,

$\mathbf{t}, \mathbf{p}$-parameters of linear combinations: scores,

$\mathbf{q}, \mathbf{u}$-parameters of linear combinations: loadings,

$\mathbf{T}, \mathbf{Q}$-block scoring matrix ( $\mathrm{n} X \mathrm{a})$,

$\mathbf{P}^{T}, \mathbf{U}^{T}$-block loading matrix (a $\mathrm{X} \mathrm{m}$ ).

The PLSR method, in the classical form based on the NIPALS iterative algorithm, leads to finding vectors $\mathbf{w}$ and $\mathbf{c}$ (normalized vectors $\mathbf{t}$ and $\mathbf{u}$ ) in order to consequently maximize the covariance between the projected input and output variable space to the normalized directions $\mathbf{t}$ and $\mathbf{u}$, respectively ( $w$ and c) [27]:

$$
[\operatorname{cov}(\mathbf{t}, \mathbf{u})]^{2}=[\operatorname{cov}(\mathbf{X w}, \mathbf{Y} \mathbf{c})]^{2}=\max _{|\mathbf{r}|=|\mathbf{s}|=1}[\operatorname{cov}(\mathbf{X r}, \mathbf{Y s})]^{2}
$$

As a result, using the NIPALS iterative procedure [25] the decomposition of the vectors of the state of the input variables and the dependent variable (1) and (2) was obtained, as assumed at the beginning. The individual component vectors of the matrix $\mathbf{P}$ are the tangent coefficients of the subsequent principal components identified during the construction of the PLSR model.

\subsection{Database of Buildings}

The information used in this research was collected during technical condition inventories of 138 buildings with reinforced concrete prefabricated structure carried out in 2002, 2007 and 2012. 64 of these structures were built in the large-block system (Figure 1a) and 74 were built in large-panel system (Figure 1b). All buildings located in the database constitute buildings in the mining area of the Legnica-Głogów Copper District (LGCD). In addition to construction data, the database contains information on indicators describing the risk of mining impacts.

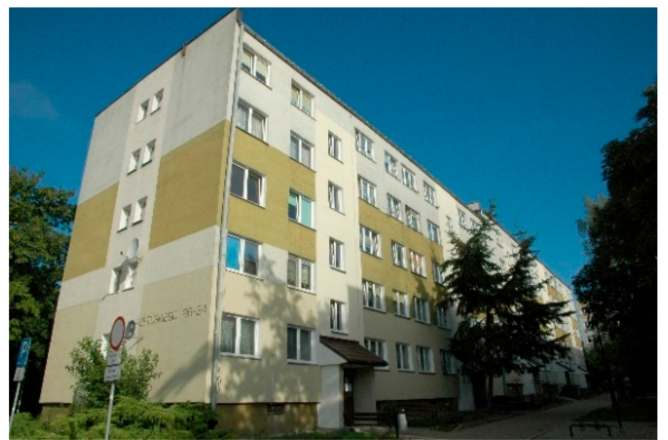

(a)

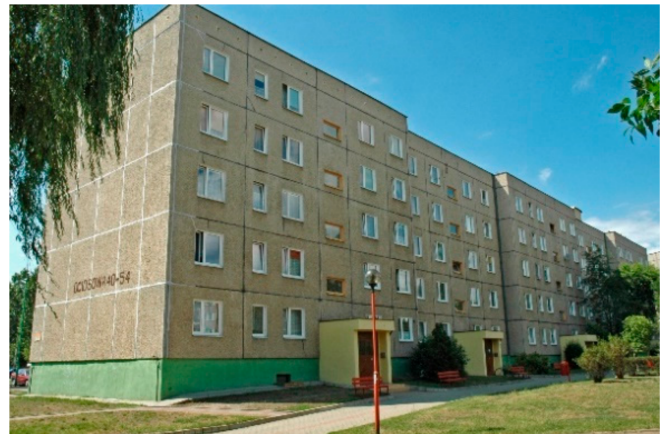

(b)

Figure 1. Example of a large-block (a) and a large-panel building (b). 


\subsubsection{Technical Characteristics of Large-Block Buildings}

Among the 64 large-block buildings collected in the database, 50 have a residential function, 13 are public utility buildings, while one object has a residential-commercial function. The public facilities were built in the school large block (SLB) system and the rest in the large block (LB) system. Most of the large-block objects are located in multi-segment buildings. In $93.7 \%$ of cases, these buildings have no more than five stories. The dominant construction system is the transverse system of load-bearing walls. The described buildings are characterized by high stiffness, which results from the nature of the reinforced concrete prefabricated structure made of what is called "Żeran brick". The structure consists of wall plates connected to each other by vertical joints and horizontally stiffened by floor slabs connected to the walls by tie beam. The foundation and basement walls of all investigated buildings are made as RC or concrete. The ceilings are made as precast reinforced concrete.

\subsubsection{Technical Characteristics of Large-Panel Buildings}

All 74 large-panel buildings collected in the database have a residential function. A total of 42 of them were erected in WWP system, and the rest in Wk-70 or Wk-70/SG system. A major part of the buildings was erected in semi-compact $(40.5 \%)$ or compact $(28.4 \%)$ development. In $87.8 \%$ of cases, these buildings have four or five storeys. In the remaining cases it is eleven storeys. The dominant system of load-bearing walls, similar as in the case of large-block buildings, is transverse. The described group of buildings is characterized by construction consisting of precast reinforced concrete elements, wall panels connected with each other with, e.g., steel connectors and concrete. Horizontal stiffness in the WWP system is ensured by reinforced concrete slabs, while in the Wk-70 system there are hollow-core slabs which are also used in large-block systems. The foundation and basement walls of described objects were made as RC or concrete.

\subsubsection{Building Technical Condition Indicators Degree of Technical Wear}

The measure of the technical condition of a building structure is its technical wear $s_{z}$ (e.g., [9]). In this study, the degree of technical wear was determined for individual buildings using the weighted average method, considering individual constructional and technological solutions. The examined objects are characterized by the degree of wear with average values from $17.8 \%$ in 2002 to $25.1 \%$ in 2012 for large-panel, and from $27.4 \%$ in 2002 to $36.7 \%$ in 2012 for large-block buildings.

\section{Damage Intensity Index}

In order to investigate the contribution of damage to the technical wear of buildings, changes in damage intensity over time and the relationship between the extent of damage and the impact of mining exploitation, a qualitative index of damage intensity $w_{u i}$ was determined for individual structural and non-structural elements (e.g., [21,22]). A total of 22 elements were identified (Table 1), for which this index was defined on a 6-point scale, in which $w_{u i}=0$ means no damage, $w_{u i}=1$-insignificant damage (range from 0 to $10 \%$ ), $w_{u i}=2$-moderate damage (range from above 10 to $30 \%$ ), $w_{u i}=3$-intensive damage (range from above 30 to $50 \%$ ), $w_{u i}=4$ (and 5) -very intensive damage (range above $50 \%$ ). Figure 2 shows examples of damage to the load-bearing structure and secondary components. 
Table 1. Intensity indices of damage to components of a building structure [22].

\begin{tabular}{|c|c|}
\hline Designation & Index Description \\
\hline \multicolumn{2}{|r|}{ Components of load-bearing structure } \\
\hline$w_{u 1}$ & Intensity of damage to foundations \\
\hline$w_{u 2}$ & Intensity of damage to load-bearing walls of the basement or to foundation walls \\
\hline$w_{u 3}$ & $\begin{array}{l}\text { Intensity of damage to interior and exterior overground load-bearing walls } \\
\text { (including lintels and walls under windows) }\end{array}$ \\
\hline$w_{u 4}$ & Intensity of damage to firewalls \\
\hline$w_{u 5}$ & $\begin{array}{l}\text { Intensity of damage to components of framed load-bearing structure } \\
\text { (columns, transoms) }\end{array}$ \\
\hline$w_{u 6}$ & Intensity of damage to ceilings over basements \\
\hline$w_{u 7}$ & Intensity of damage to ceilings over higher levels, flat roof (roof covering) \\
\hline$w_{u 8}$ & Intensity of damage to stairs \\
\hline$w_{u 9}$ & Intensity of damage to balconies and loggias (as well as eaves and cornices) \\
\hline$w_{u 10}$ & Intensity of damage to roof structure \\
\hline \multicolumn{2}{|r|}{ Secondary components (finishing elements) } \\
\hline$w_{u 11}$ & Intensity of damage to partition walls \\
\hline$w_{u 12}$ & Intensity of damage to internal plasters and wall cladding \\
\hline$w_{u 13}$ & Intensity of damage to floors (floor layers) \\
\hline$w_{u 14}$ & Intensity of damage to chimney walls \\
\hline$w_{u 15}$ & Intensity of damage to bracings (elements ensuring spatial rigidity) \\
\hline$w_{u 16}$ & Intensity of damage to infill (or curtain) walls \\
\hline$w_{u 17}$ & Intensity of damage to facade (facade layers) \\
\hline$w_{u 18}$ & Intensity of damage to damp-proof insulation \\
\hline$w_{u 19}$ & Intensity of damage to roofing \\
\hline$w_{u 20}$ & Intensity of damage to flashings, gutters and downpipes \\
\hline$w_{u 21}$ & Intensity of damage to joinery \\
\hline$w_{u 22}$ & $\begin{array}{l}\text { Intensity of damage to exterior elements (entrances to buildings, platforms, terraces, } \\
\text { wall trims, etc.) }\end{array}$ \\
\hline
\end{tabular}

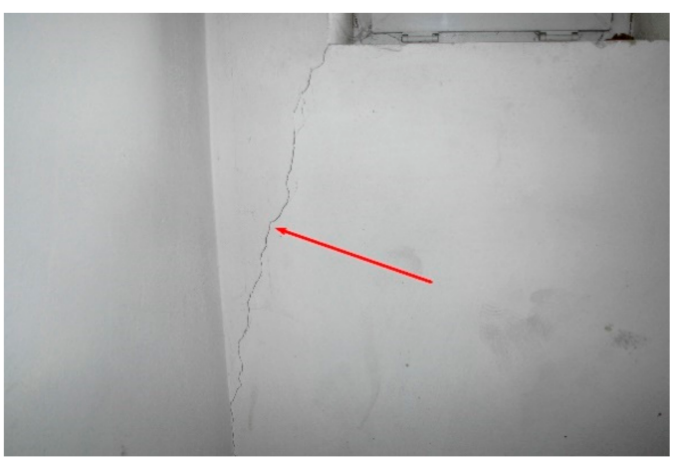

(a)

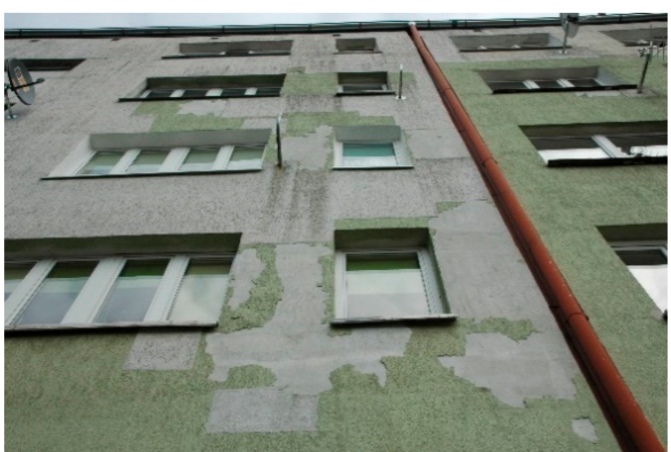

(b)

Figure 2. Examples of damage to load-bearing basement walls $w_{u 2}$ (a) and facade layers $w_{u 17}(\mathbf{b})$.

The analysis of the value of the damage intensity index $w_{u i}$ for individual building elements in the studied groups showed that there was insignificant, moderate or, in individual cases, intensive damage. 
The damage intensity index of entire buildings was then determined as linear combinations of the indices describing the damage of their component parts. The partial least squares regression (PLSR) approach from data mining presented in Section 2 was used to update the generalized damage index formula $w_{u}$.

Taking into account the specificity of the studied buildings, it was found that the description of the generalized damage index $w_{u}$ for the studied groups of buildings are linear combinations (Table 2) of the damage indices of structural and finishing elements $w_{u i}$ with the general form of the formula:

$$
w_{u}=a_{1} w_{u 1}+\ldots+a_{n} w_{u n}
$$

Table 2. Directional coefficients of the linear combination of components occurring at individual damage indices determined by the PLSR method.

\begin{tabular}{cccccccccccc}
\hline Group of Buildings & $\boldsymbol{a}_{\mathbf{2}}$ & $\boldsymbol{a}_{\mathbf{3}}$ & $\boldsymbol{a}_{\mathbf{7}}$ & $\boldsymbol{a}_{\mathbf{9}}$ & $\boldsymbol{a}_{\mathbf{1 1}}$ & $\boldsymbol{a}_{\mathbf{1 2}}$ & $\boldsymbol{a}_{\mathbf{1 3}}$ & $\boldsymbol{a}_{\mathbf{1 7}}$ & $\boldsymbol{a}_{\mathbf{2 0}}$ & $\boldsymbol{a}_{\mathbf{2 2}}$ \\
\hline Large-block & 0.057 & 0.058 & 0.064 & - & 0.039 & 0.015 & 0.037 & 0.044 & - & - \\
\hline Large-panel & 0.054 & 0.048 & 0.031 & 0.031 & 0.061 & 0.053 & 0.046 & 0.034 & 0.037 & 0.015 \\
\hline
\end{tabular}

The formula calculated for large-block buildings does not take into account the values of indicators $w_{u 9}, w_{u 20}, w_{u 22}$, as contrary to large-panel buildings, they turned out to be insignificant in this group. The $w_{u}$ values determined for particular buildings fall within the categories of insignificant and moderate.

The average rate of technical wear presented in Table 3 and Figure 3 indicates a very similar rate of wear growth between 2002 and 2007 in the group of large-block (by 4.3\% over five years) and large-panel buildings (by 4.1\% over five years). Between 2007 and 2012, an increase in the rate of consumption growth was recorded in the group of large-block (up to $5.0 \%$ over five years) and a decrease in the group of large-panel buildings (down to $3.2 \%$ over five years). This situation may be caused by differences in the quality of maintenance of buildings. In the group of large-block buildings, between 2002 and 2007 there was a much higher number of renovations carried out than between 2007 and 2012. This is particularly true for public utility buildings (including schools), which are exposed to accelerated wear due to their operating conditions.

Table 3. Characteristics of the technical condition of the studied groups of buildings.

\begin{tabular}{ccccccc}
\hline Group of Buildings & \multicolumn{2}{c}{ Large-Block } & \multicolumn{3}{c}{ Large-Panel } \\
\hline Inventory Year & $\mathbf{2 0 0 2}$ & $\mathbf{2 0 0 7}$ & $\mathbf{2 0 1 2}$ & $\mathbf{2 0 0 2}$ & $\mathbf{2 0 0 7}$ & $\mathbf{2 0 1 2}$ \\
\hline Average age & 27.8 & 32.8 & 37.8 & 18.6 & 23.6 & 28.6 \\
\hline Average degree of technical wear $s_{z}[\%]$ & 27.4 & 31.7 & 36.7 & 17.8 & 21.9 & 25.1 \\
\hline Average building damage intensity index $w_{u}[\%]$ & 6.0 & 6.7 & 7.3 & 5.9 & 7.3 & 7.9 \\
\hline Damage contribution in technical wear $\left(w_{u} / s_{z}\right)[\%]$ & $22 \%$ & $21 \%$ & $20 \%$ & $33 \%$ & $33 \%$ \\
\hline $\begin{array}{c}\text { Increase in average damage intensity index } w_{u} \\
\text { between consecutive inventories }[\%]\end{array}$ & - & 0.7 & 0.6 & - & \multirow{2}{*}{1.4} \\
\hline
\end{tabular}

In 2002, the average values of the damage intensity index in the compared groups of buildings were similar at the level of $5.9 \div 6.0 \%$ (Figure 4 ). In the group of large-block buildings, a similar rate of increase of the damage index was observed between 2002 and 2012 , at the level of $0.6 \div 0.7 \%$, while among the large-panel buildings an increase of the index by $1.4 \%$ until 2007 and by $0.6 \%$ until 2012 was observed. 


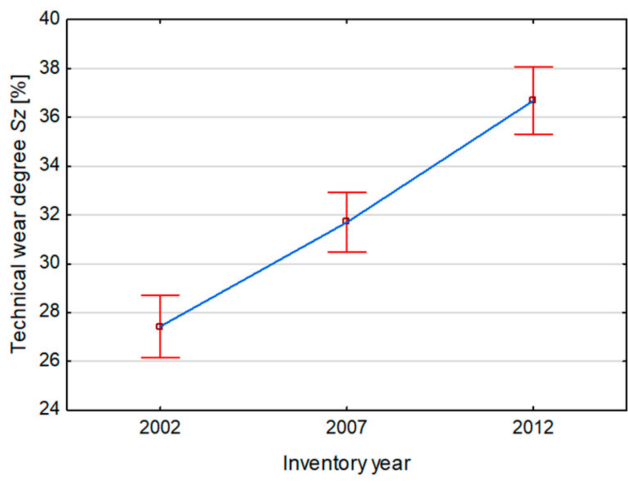

(a)

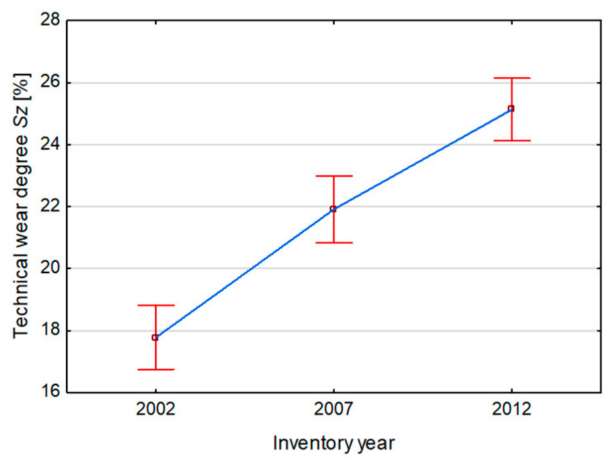

(b)

Figure 3. Average degree of technical wear of large-block (a) and large-panel (b) buildings, determined on the basis of the 2002, 2007 and 2012 inventories.

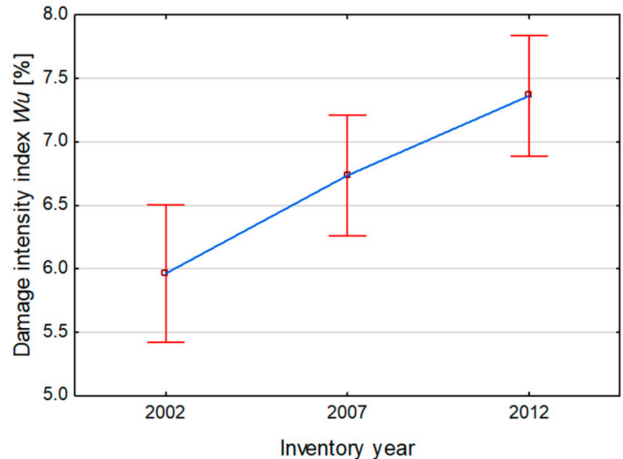

(a)

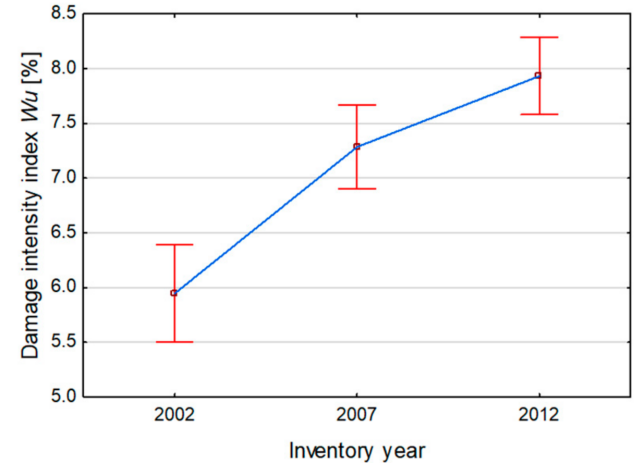

(b)

Figure 4. Average values of the damage intensity index for large-block (a) and large-panel (b) buildings based on the 2002, 2007, and 2012 inventories.

\subsubsection{Indicators Describing the Risk of Mining Impacts on Buildings}

Continuous Surface Deformation Hazard Index

Taking into account the specificity of continuous ground deformations in the LGCD and the character of the analysed buildings (large-block and large-panel buildings, in most cases up to five storeys in height), the horizontal strain of ground $\varepsilon$ was assumed as the basic measure of threat of continuous surface deformations. On the basis of information obtained from mines about mining exploitation performed in the studied regions, each building was assigned a maximum value of horizontal deformation $\varepsilon_{\max }$, which occurred in the analysed periods of building existence, i.e., from the date of construction to 2002, then in 2003-2007 and in 2008-2012.

The obtained values of $\varepsilon_{\max }$ are within the limits of mining site Categories I and II for most cases (Table 4 and Figure 5).

Table 4. Summary of average values of indicators describing the hazard for buildings from mining impacts.

\begin{tabular}{cccc}
\hline Inventory Year & $\mathbf{2 0 0 2}$ & $\mathbf{2 0 0 7}$ & $\mathbf{2 0 1 2}$ \\
\hline Average of the maximum values of horizontal deformation $\varepsilon_{\max }[\mathrm{mm} / \mathrm{m}]$ & 1.73 & 1.60 & 1.53 \\
\hline Average of the maximum horizontal components of the vibration acceleration $P G A_{H}\left[\mathrm{~m} / \mathrm{s}^{2}\right]$ & 0.76 & 0.91 & 0.26 \\
\hline Average impact of tremors on technical wear $a_{s g}\left[\mathrm{~m} / \mathrm{s}^{2}\right]$ & 2.74 & 3.15 & 3.19 \\
\hline Average number of tremors with $P G A_{H} \geq a_{p}=0.12 \mathrm{~m} / \mathrm{s}^{2} \mathrm{~N}$ [pcs.] & 166 & 35 \\
\hline
\end{tabular}




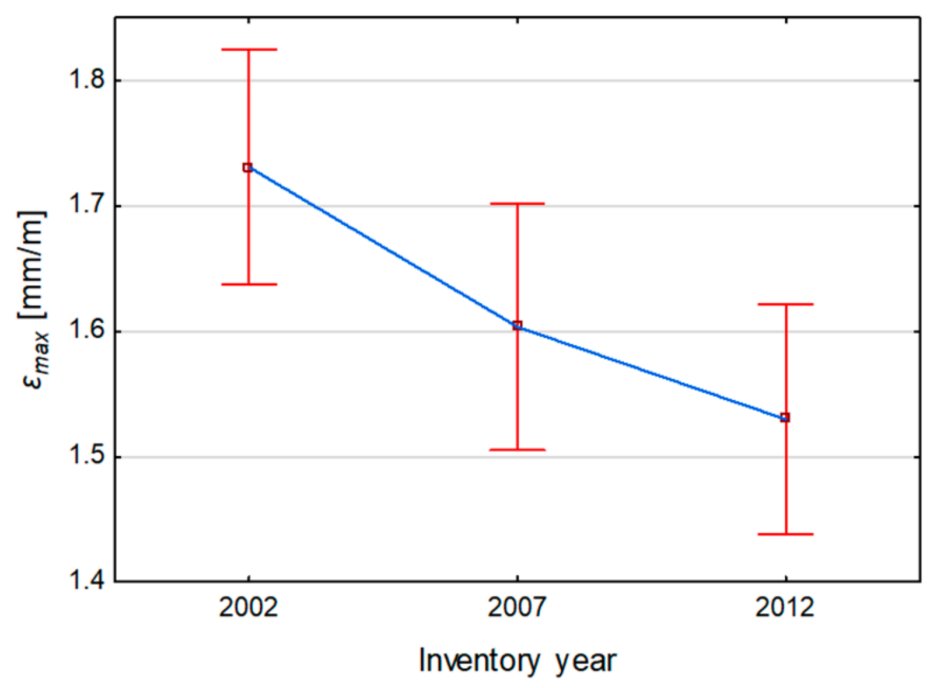

Figure 5. Average values of $\varepsilon_{\max }[\mathrm{mm} / \mathrm{m}]$. Mining tremors hazard indicators.

In case of evaluation of the safety of the structures, the horizontal component of vibration acceleration $P G A_{H}$ (horizontal peak ground acceleration) or its velocity $P G V_{H}$ (horizontal peak ground velocity) is generally taken as the basic indicator for evaluating the risk of mining tremors. Therefore, the multiplicity of tremors acting on the building is not taken into account.

Such a procedure does not allow evaluation of the influence of tremors on technical wear of a building. The analysis should take into account repeatability of tremors, i.e., the number and individual intensities of all seismic phenomena significantly affecting the object during its lifetime.

A research paper [30] presents the concept of $a_{s g}$ (geometric sum of maximum horizontal accelerations) index, which is a measure of the effects of mining tremors on the technical wear of buildings. It was defined as the geometric sum of peak values of the horizontal component of ground vibration acceleration at the building foundation. Taken into account were only those tremors that occurred during the lifetime of the building and whose peak values at its location are higher than a preset threshold value $a_{p}$, below which the impact of the tremor on the technical wear of the building is considered negligible. Studies presented in [30] have shown that the optimal threshold value is $a_{p}=0.12 \mathrm{~m} / \mathrm{s}^{2}$. The value of $a_{s g}$ index was calculated by the formula:

$$
a_{s g}(x, y)=\sqrt{\sum_{k=1}^{n} P G A_{H k}(x, y)^{2}} ; P G A_{H k}(x, y) \geq a_{p}
$$

On the basis of the mine catalogues of tremors for individual buildings, the $P G A_{H}$ values from all recorded seismic phenomena in the individual analysed time intervals (from the date of construction to 2002, in 2003-2007 and in 2008-2012) were determined. They range from 0.15 to $1.38\left[\mathrm{~m} / \mathrm{s}^{2}\right]$.

For the $a_{s g}$ index, all tremors that occurred during the entire lifetime of the facility and whose peak acceleration values at the site were higher than $a_{p}=0.12 \mathrm{~m} / \mathrm{s}^{2}$ were considered (Table 4 and Figure 6). The $a_{s g}$ values ranged from 2.10 to $3.45\left[\mathrm{~m} / \mathrm{s}^{2}\right]$. 


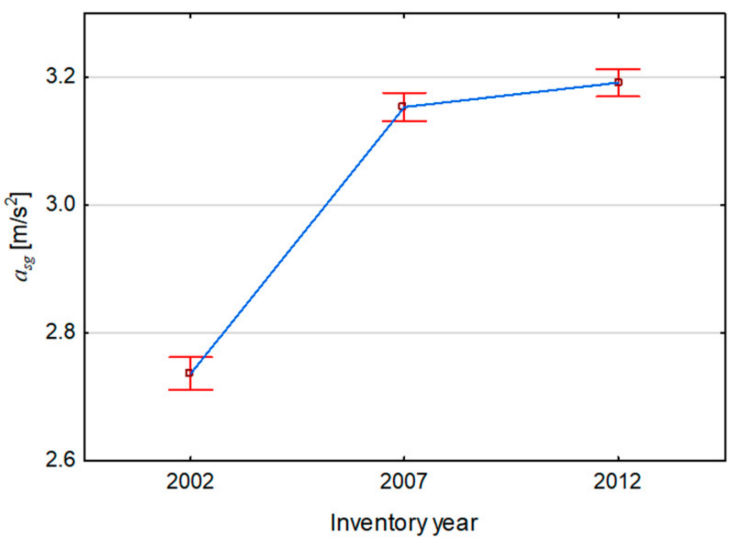

(a)

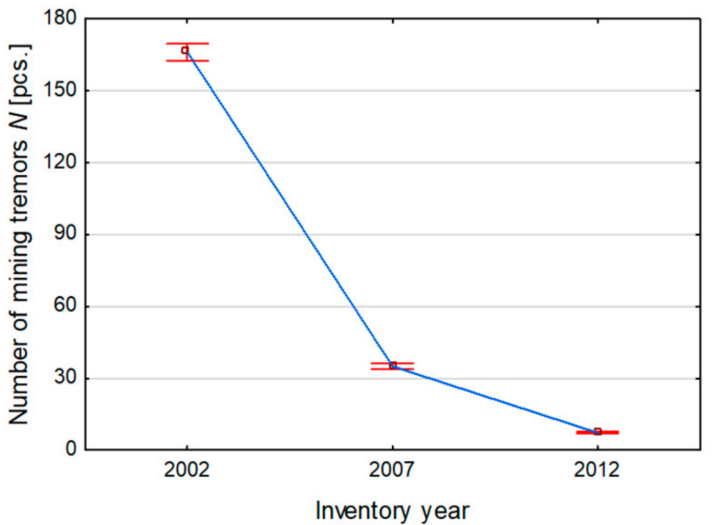

(b)

Figure 6. Average $a_{s g}$ values of the studied buildings (a) and average number of $\mathrm{N}$ tremors with $a_{p} \geq 0.12 \mathrm{~m} / \mathrm{s}^{2}(\mathbf{b})$.

\section{Results and Discussions}

\subsection{Analysis of Changes in the Intensity of Building Damage and Mining Impacts over Time}

Tables 3 and 4 and Figures 3-6 present the changes over time of the average values of the technical condition parameters $\left(s_{z}, w_{u}\right)$ and indicators of the development hazard from mining impact $\left(\varepsilon_{\max }, P G A_{H}\right.$ i $\left.a_{s g}\right)$.

It was found that with the passage of time not only the degree of wear $s_{z}$ of the studied buildings increases, but also the extent of their damage represented by $w_{u}$. Despite the increase in natural wear associated with the passage of time, as a result of repairs and maintenance of the studied buildings, a decrease in the contribution of damage in technical wear $\left(w_{u} / s_{z}\right)$ is observed from $22 \%$ in 2002 to $20 \%$ in 2012 for large-block buildings and from $33 \%$ to $31 \%$ for large-panel buildings. This may also indicate a decrease in the intensity of impacts that are potential causes of damage. The results of the dependency analyses in the studied groups of buildings are certainly influenced by construction-material differentiation and age difference. For example, large-block buildings are on average more than nine years older than the buildings built with large-panel technology, and this allows us to think that natural wear directly related to the age of the building plays a bigger role in the technical wear of large-block buildings.

The analysis of trends in changes of average values of mining influence indicators, i.e., $\varepsilon_{\max }$ and $P G A_{H}$, indicates that in recent years there has been a decrease in both the values of horizontal ground deformation and the intensity of mining tremors.

With lower parameters of the most intense tremors (decrease in the average value of the $P G A_{H}$ index), there is a smaller increase in the value of the $a_{s g}$ index, which also takes into account the repetition of tremors affecting the building.

\subsection{Research on the Relationship between the Extent of Damage Intensity Index and Mining Impacts}

The purpose of this study was to see if there was a significant relationship between the damage intensity index of buildings $w_{u}$ and their components $w_{u i}$, and mining impacts in the form of:

- Continuous ground deformations, described by maximum values of horizontal deformations $\varepsilon_{\max }$,

- Mining tremors, which were measured using two indices $P G A_{H}$ and $a_{s g}$.

They were determined individually for each building. In the case of $P G A_{H}$, all tremors which occurred in the analysed periods of the building existence were taken into account, that is from the date of construction to 2002, in 2003-2007 and 2008-2012. In the case of $a_{s g}$, the basis was the increments of the index over the reported time intervals. 
Pearson's linear correlation test was used. In addition to the correlation coefficient $\mathrm{R}$, the significance level $p$ of the obtained result was also calculated. The critical level was taken as $p=0.05$.

The results of the conducted research for large-block buildings are summarized in Table 5, while those for large-panel buildings in Table 6 . The cases where significant positive correlations were found are highlighted.

Table 5. Correlation tests between $w_{u i}$ index and indicators of surface deformation influence $\left(\varepsilon_{\max }\right)$ and mining tremor influence $\left(a_{s g}\right.$ and $\left.P G A_{H}\right)$ performed for large-block buildings. Significant values are bolded.

\begin{tabular}{ccccccc}
\hline $\begin{array}{c}\text { Damage } \\
\text { Intensity Index }\end{array}$ & $\begin{array}{c}\text { Correlations between } \\
w_{u i} \text { and } \varepsilon_{\text {max }}\end{array}$ & $\begin{array}{c}\text { Correlations between } \\
w_{u \boldsymbol{i}} \text { and } \boldsymbol{a}_{\boldsymbol{s g}}\end{array}$ & \multicolumn{2}{c}{$\begin{array}{c}\text { Correlations between } \\
\boldsymbol{w}_{\boldsymbol{u}} \text { and } \boldsymbol{P G} \boldsymbol{A}_{\boldsymbol{H}}\end{array}$} \\
\hline$w_{u i}$ & $R$ & $p$ & $R$ & $p$ & $R$ & $p$ \\
\hline$w_{u 2}$ & 0.071 & 0.325 & $\mathbf{0 . 7 6 3}$ & $\mathbf{0 . 0 0 0}$ & 0.061 & 0.402 \\
\hline$w_{u 3}$ & $\mathbf{0 . 1 5 4}$ & $\mathbf{0 . 0 3 3}$ & $\mathbf{0 . 8 5 2}$ & $\mathbf{0 . 0 0 0}$ & 0.096 & 0.186 \\
\hline$w_{u 7}$ & $\mathbf{0 . 1 4 3}$ & $\mathbf{0 . 0 4 8}$ & $\mathbf{0 . 7 0 7}$ & $\mathbf{0 . 0 0 0}$ & 0.072 & 0.318 \\
\hline$w_{u 11}$ & $\mathbf{0 . 1 5 1}$ & $\mathbf{0 . 0 3 6}$ & $\mathbf{0 . 8 5 3}$ & $\mathbf{0 . 0 0 0}$ & 0.099 & 0.174 \\
\hline$w_{u 12}$ & $\mathbf{0 . 1 5 8}$ & $\mathbf{0 . 0 2 8}$ & $\mathbf{0 . 6 9 0}$ & $\mathbf{0 . 0 0 0}$ & -0.086 & 0.234 \\
\hline$w_{u 13}$ & 0.137 & 0.058 & $\mathbf{0 . 7 9 8}$ & $\mathbf{0 . 0 0 0}$ & $\mathbf{0 . 1 5 7}$ & $\mathbf{0 . 0 2 9}$ \\
\hline$w_{u 17}$ & 0.074 & 0.307 & $\mathbf{0 . 5 0 1}$ & $\mathbf{0 . 0 0 0}$ & $\mathbf{0 . 2 1 3}$ & $\mathbf{0 . 0 0 3}$ \\
\hline$w_{u}$ & $\mathbf{0 . 1 4 5}$ & $\mathbf{0 . 0 4 5}$ & $\mathbf{0 . 8 6 6}$ & $\mathbf{0 . 0 0 0}$ & 0.122 & 0.093 \\
\hline
\end{tabular}

$R$-correlation coefficient, $p$-significance level.

Table 6. Correlation tests between $w_{u i}$ index and indicators of surface deformation influence $\left(\varepsilon_{\max }\right)$ and mining tremor influence $\left(a_{s g}\right.$ and $\left.P G A_{H}\right)$ performed for large-panel buildings. Significant values are bolded.

\begin{tabular}{ccccccc}
\hline $\begin{array}{c}\text { Damage } \\
\text { Intensity Index }\end{array}$ & $\begin{array}{c}\text { Correlations between } \\
w_{u i} \text { and } \varepsilon_{\text {max }}\end{array}$ & $\begin{array}{c}\text { Correlations between } \\
w_{u i} \text { and } \boldsymbol{a}_{\boldsymbol{s g}}\end{array}$ & \multicolumn{2}{c}{$\begin{array}{c}\text { Correlations between } \\
\boldsymbol{w}_{\boldsymbol{u}} \text { and } \mathbf{P G} \boldsymbol{A}_{\boldsymbol{H}}\end{array}$} \\
\hline$w_{u i}$ & $R$ & $p$ & $R$ & $p$ & $R$ & $p$ \\
\hline$w_{u 2}$ & $\mathbf{0 . 1 6 1}$ & $\mathbf{0 . 0 1 7}$ & $\mathbf{0 . 8 0 0}$ & $\mathbf{0 . 0 0 0}$ & $\mathbf{0 . 3 8 4}$ & $\mathbf{0 . 0 0 0}$ \\
\hline$w_{u 3}$ & $\mathbf{0 . 1 3 8}$ & $\mathbf{0 . 0 4 1}$ & $\mathbf{0 . 8 1 7}$ & $\mathbf{0 . 0 0 0}$ & $\mathbf{0 . 3 3 9}$ & $\mathbf{0 . 0 0 0}$ \\
\hline$w_{u 7}$ & 0.100 & 0.140 & $\mathbf{0 . 7 1 8}$ & $\mathbf{0 . 0 0 0}$ & $\mathbf{0 . 3 4 8}$ & $\mathbf{0 . 0 0 0}$ \\
\hline$w_{u 9}$ & 0.073 & 0.283 & $\mathbf{0 . 3 1 0}$ & $\mathbf{0 . 0 0 0}$ & 0.062 & 0.356 \\
\hline$w_{u 11}$ & $\mathbf{0 . 1 5 0}$ & $\mathbf{0 . 0 2 6}$ & $\mathbf{0 . 6 9 8}$ & $\mathbf{0 . 0 0 0}$ & $\mathbf{0 . 3 5 3}$ & $\mathbf{0 . 0 0 0}$ \\
\hline$w_{u 12}$ & 0.127 & 0.059 & $\mathbf{0 . 8 2 7}$ & $\mathbf{0 . 0 0 0}$ & $\mathbf{0 . 4 0 1}$ & $\mathbf{0 . 0 0 0}$ \\
\hline$w_{u 13}$ & $\mathbf{0 . 1 3 5}$ & $\mathbf{0 . 0 4 5}$ & $\mathbf{0 . 6 5 7}$ & $\mathbf{0 . 0 0 0}$ & $\mathbf{0 . 4 0 1}$ & $\mathbf{0 . 0 0 0}$ \\
\hline$w_{u 17}$ & 0.092 & 0.173 & $\mathbf{0 . 7 5 9}$ & $\mathbf{0 . 0 0 0}$ & $\mathbf{0 . 3 5 9}$ & $\mathbf{0 . 0 0 0}$ \\
\hline$w_{u 20}$ & $\mathbf{0 . 2 1 9}$ & $\mathbf{0 . 0 0 1}$ & $\mathbf{0 . 6 0 3}$ & $\mathbf{0 . 0 0 0}$ & $\mathbf{0 . 1 9 3}$ & $\mathbf{0 . 0 0 4}$ \\
\hline$w_{u 22}$ & -0.014 & 0.841 & $\mathbf{0 . 4 6 9}$ & $\mathbf{0 . 0 0 0}$ & $\mathbf{0 . 3 5 7}$ & $\mathbf{0 . 0 0 0}$ \\
\hline$w_{\boldsymbol{u}}$ & $\mathbf{0 . 1 5 6}$ & $\mathbf{0 . 0 2 0}$ & $\mathbf{0 . 8 9 1}$ & $\mathbf{0 . 0 0 0}$ & $\mathbf{0 . 4 2 7}$ & $\mathbf{0 . 0 0 0}$ \\
\hline$R$
\end{tabular}

$R$-correlation coefficient, $p$-significance level.

\subsubsection{Dependence of Damage Intensity of Large-Block Buildings on Mining Impacts}

The results presented in Table 5 show significant correlations between horizontal ground deformations $\varepsilon_{\max }$ and indices:

- Intensity of damage to interior and exterior overground load-bearing walls (including lintels and walls under windows) $w_{u 3}$,

- Intensity of damage to ceilings over higher levels, flat roof (roof covering) $w_{u 7}$, 
- Intensity of damage to partition walls $w_{u 11}$,

- Intensity of damage to internal plaster and wall cladding $w_{u 12}$.

The results of correlation tests between maximum acceleration components $P G A_{H}$ and damage intensity indices has only showed significant correlations for floors $w_{u 13}$ and facade layers $w_{u 17}$.

The highest correlation coefficients with values of $R=0.501 \div 0.853$ were obtained between the $a_{s g}$ index describing the influence of mining tremors and the damage indices of all significant elements.

In addition, for the horizontal ground deformations $\varepsilon_{\max }$ and the mining tremors index $a_{s g}$, significant correlations were found with the $w_{u}$ index determined for the whole building, which are 0.145 and 0.866 , respectively. The significance level of the $P G A_{H}$ index was close to the critical level $(p=0.05)$.

\subsubsection{Dependence of Damage Intensity of Large-Panel Buildings on Mining Impacts}

The results presented in Table 6 show significant correlations between horizontal ground deformations $\varepsilon_{\max }$ and indices:

- Intensity of damage to load-bearing walls of the basement or to foundation walls $w_{u 2}$,

- Intensity of damage to interior and exterior overground load-bearing walls (including

lintels and walls under windows) $w_{u 3}$

- Intensity of damage to partition walls $w_{u 11}$,

- Intensity of damage to floors (floor layers) $w_{u 13}$,

- Intensity of damage to flashings, gutters and downpipes $w_{u 20}$.

The results of the correlation study between the damage indices $w_{u i}$ and the maximum horizontal components of vibration acceleration $P G A_{H}$ indicate a significant correlation $\mathrm{R}=0.193 \div 0.401$ with the damage of all analysed building elements except for the damage to balconies and loggias (as well as eaves and cornices) $w_{u 9}$.

The highest correlation coefficients with values of $R=0.310 \div 0.827$, as in the case of large-block buildings, were shown between the index describing the influence of mining tremors $a_{s g}$, and the damage indices of all significant elements.

For both maximum deformation $\varepsilon_{\max }$ and the effect of $a_{s g}$ and PGA $A_{H}$ tremors, significant correlations were found with the $w_{u}$ index determined for the whole building, which are $0.156,0.891$, and 0.427 , respectively.

The biggest share in the variability of the damage intensity index for both largeblock and large-panel buildings is determined by the $a_{s g}$ tremors index. As shown in Tables 4 and 5, it obtains much higher values of correlation than the $P G A_{H}$ index. This confirms that its definition is correct. Slightly higher values of correlation occur in case of large-panel buildings. This may be caused by repair work, which influences the total elimination or reduction of the scope of damages. Large-panel buildings are on average nine years younger and the scale of renovations they have been undergone so far is lower than in case of objects erected in large-block technology.

\section{Conclusions}

The subject of this study was a group of 138 prefabricated reinforced concrete buildings, consisting of 64 buildings in large-block technology and 74 buildings in large-panel technology. All buildings are located in the mining area of the LGCD and over their entire lifetime they have been subjected to mining impacts in the form of continuous ground deformation and mining tremors. The results of the analysis of the change over time in the intensity of their damage, found in the three inventories conducted in 2002, 2007 and 2012 , and the relationship between the extent of their damage and the impact of mining exploitation are presented.

The research was based on the level of technical wear of the buildings $s_{z}$ and on the damage intensity indices $w_{u i}$ for constructional and secondary components. Using the PLSR method and the extended database, linear formulas of generalized damage index $w_{u}$ were verified for groups of large-block and large-panel buildings. Based on the obtained 
formulas, the generalized damage index $w_{u}$ and the increments of the damage index which occurred in the periods between successive inventories were determined. Each building was assigned the maximum values of mining impact indices which occurred in the analysed periods of building existence, i.e., from the date of construction to 2002, then in 2003-2007 and in 2008-2012. The index describing the impact of continuous ground deformations $\varepsilon_{\max }$ and indices representing dynamic impacts: $a_{s g}$ and $P G A_{H}$ were adopted.

The analysis of changes in the damage intensity index of the analysed buildings during their 10-year period of use confirmed a continuous increase in the scope of damage represented by the $w_{u}$ index. In case of large-block buildings, the damage intensity growth rate remains at a similar level. It is different in case of large-panel buildings, where after a significant increase of $w_{u}$ index by $1.4 \%$ in the period of 5 years between 2002 and 2007, in the last five-year period it increases by $0.6 \%$.

In the ten years of use (2002-2012), a decrease in the share of $w_{u}$ damage in the technical wear $s_{z}$ of large-block buildings was also observed, from $22 \%$ to $20 \%$, and in the case of large-panel buildings from $33 \%$ to $31 \%$. These changes occur at lower intensities of mining impacts observed in recent years, which is evidenced by a decrease in the average values of the indicators of the hazard of the analysed buildings from mining impacts ( $\varepsilon_{\max }$ and $\left.P G A_{H}\right)$ and a decrease in the growth of the $a_{s g}$ index.

In turn, the results of the research on the dependence of the scope of damage to buildings on the mining impact indicate significant correlations between the $w_{u}$ index determined for the whole building and the damage to its elements and the dynamic impact index $a_{s g}$. In the case of horizontal ground deformation $\varepsilon_{\max }$ and peak values of ground vibration acceleration in the place of object location $P G A_{H}$, lower correlations with damage were found only for some building components. These results demonstrate the significant influence of the multiplicity of shaking impacts represented by the $a_{s g}$ index on the intensity of building damage, which confirms the results of previous analyses conducted for traditional single-family housing and LGCD masonry multi-story buildings.

Correctly identifying and classifying damage to individual components and the building as a whole provides opportunities not only for building administration, but leads to proper management, saves time, materials and money, and prevents potential defects and unplanned building shutdowns.

Author Contributions: Conceptualization, A.J., A.B., K.F. and J.R.; methodology, K.F. and J.R.; software analysis, A.J. and J.R.; validation, A.J.; formal analysis, A.B. and K.F.; investigation, A.J.; resources, A.J.; data curation, A.J., K.F. and J.R.; writing-original draft preparation, A.J.; writingreview and editing, A.J., K.F. and J.R; visualization, A.J.; supervision, A.B. and K.F.; project administration, A.B.; funding acquisition, A.B. All authors have read and agreed to the published version of the manuscript.

Funding: This research received no external funding.

Institutional Review Board Statement: Not applicable.

Informed Consent Statement: Not applicable.

Data Availability Statement: The data presented in this study are available on request from the corresponding author. The data are not publicly available because they were taken from studies carried out for private enterprises.

Conflicts of Interest: The authors declare no conflict of interest.

\section{References}

1. Kwatra, S.; Kumar, A.; Sharma, P. A critical review of studies related to construction and computation of Sustainable Development Indices. Ecol. Indic. 2020, 112, 106061. [CrossRef]

2. Manzoor, B.; Othman, I.; Durdyev, S.; Ismail, S.; Wahab, M.H. Influence of Artificial Intelligence in Civil Engineering toward Sustainable Development-A Systematic Literature Review. Appl. Syst. Innov. 2021, 4, 52. [CrossRef]

3. Chel, A.; Kaushik, G. Renewable energy technologies for sustainable development of energy efficient building. Alex. Eng. J. 2018, 57, 655-669. [CrossRef] 
4. Darabpour, M.R.; Darabpour, M.; Sardroud, J.M.; Smallwood, J.; Tabarsa, G. Practical Approaches toward Sustainable Development in Iranian Green Construction. Civ. Eng. J. 2018, 4, 2450-2465. [CrossRef]

5. Liu, C.; Fang, D.; Zhao, L. Reflection on earthquake damage of buildings in 2015 Nepal earthquake and seismic measures for post-earthquake reconstruction. Structures 2021, 30, 647-658. [CrossRef]

6. Tajduś, K.; Tajduś, A.; Cała, M. Seismicity and rock burst hazard assessment in fault zones: A case study. Arch. Min. Sci. 2018, 63, 747-765. [CrossRef]

7. Misa, R.; Sroka, A.; Tajduś, K.; Dudek, M. Analytical design of selected geotechnical solutions which protect civil structures from the effects of underground mining. J. Sustain. Min. 2018, 18, 1-7. [CrossRef]

8. Kwinta, A.; Gradka, R. Analysis of the damage influence range generated by underground mining. Int. J. Rock Mech. Min. Sci. 2020, 128, 104263. [CrossRef]

9. Ścigała, R.; Szafulera, K. Linear discontinuous deformations created on the surface as an effect of underground mining and local geological conditions-case study. Bull. Eng. Geol. Environ. 2019, 79, 2059-2068. [CrossRef]

10. Wodyński, A. Zużycie Techniczne Budynków na Terenach Górniczych (Technical Wear of Buildings in Mining Areas); AGH Publishing House: Cracow, Poland, 2007.

11. Ostrowski, J.; Ćmiel, A. The Use of a Logit Model to Predict the Probability of Damage to Bullding Structures in Mining Terrains Arch. Min. Sci. 2008, 53, 161-182. Available online: https:/ /www.infona.pl//resource/bwmeta1.element.baztech-article-BPZ2-0 036-0029 (accessed on 7 November 2021).

12. Konior, J.; Sawicki, M.; Szóstak, M. Influence of Age on the Technical Wear of Tenement Houses. Appl. Sci. 2021, 11, 297. [CrossRef]

13. Konior, J.; Sawicki, M.; Szóstak, M. Damage and Technical Wear of Tenement Houses in Fuzzy Set Categories. Appl. Sci. 2021, 11, 1484. [CrossRef]

14. Kliestik, T.; Valaskova, K.; Nica, E.; Kovacova, M.; Lazaroiu, G. Advanced methods of earnings management: Monotonic trends and change-points under spotlight in the Visegrad countries. Oeconomia Copernic. 2020, 11, 371-400. [CrossRef]

15. D'Amico, B.; Myers, R.; Sykes, J.; Voss, E.; Cousins-Jenvey, B.; Fawcett, W.; Richardson, S.; Kermani, A.; Pomponi, F. Machine Learning for Sustainable Structures: A Call for Data. Structures 2019, 19, 1-4. [CrossRef]

16. Marzouk, M.; Azab, S.; Metawie, M. BIM-based approach for optimizing life cycle costs of sustainable buildings. J. Clean. Prod. 2018, 188, 217-226. [CrossRef]

17. Geiker, M.R.; Michel, A.; Stang, H.; Lepech, M.D. Limit states for sustainable reinforced concrete structures. Cem. Concr. Res. 2019, 122, 189-195. [CrossRef]

18. Zavadskas, E.K.; Antucheviciene, J.; Vilutiene, T.; Adeli, H. Sustainable Decision-Making in Civil Engineering, Construction and Building Technology. Sustainability 2018, 10, 14. [CrossRef]

19. Siksnelyte, I.; Zavadskas, E.K.; Streimikiene, D.; Sharma, D. An Overview of Multi-Criteria Decision-Making Methods in Dealing with Sustainable Energy Development Issues. Energies 2018, 11, 2754. [CrossRef]

20. Rusek, J.; Tajduś, K.; Firek, K.; Jędrzejczyk, A. Score-based Bayesian belief network structure learning in damage risk modelling of mining areas building development. J. Clean. Prod. 2021, 296, 126528. [CrossRef]

21. Firek, K. Proposal for classification of prefabricated panel building damage intensity rate in mining areas. Arch. Min. Sci. 2009, 54, 467-479.

22. Firek, K.; Rusek, J.; Wodyński, A. Wybrane metody eksploracji danych i uczenia maszynowego w analizie stanu uszkodzeń oraz zużycia technicznego zabudowy terenów górniczych. Przegląd Górniczy 2016, 72, 50-55.

23. Firek, K. Analysis of the influence of mining impacts on the intensity of damage to masonry building structures. J. Civ. Eng. Environ. Arch. 2017, 64. [CrossRef]

24. Firek, K.; Rusek, J. Partial Least Squares Method in the Analysis of the Intensity of Damage in Prefabricated Large-Block Building Structures. Arch. Min. Sci. 2017, 62, 269-277. [CrossRef]

25. Geladi, P.; Kowalski, B.R. Partial least-squares regression: A tutorial. Anal. Chim. Acta 1986, 185, 1-17. [CrossRef]

26. Rosipal, R.; Krämer, N. Overview and Recent Advances in Partial Least Squares. In International Statistical and Optimization Perspectives Workshop "Subspace, Latent Structure and Feature Selection"; Lecture Notes in Computer Science (Including Subser. Lect. Notes Artif. Intell. Lect. Notes Bioinformatics); Springer: Berlin/Heidelberg, Germany, 2005; Volume 3940, pp. 34-51. [CrossRef]

27. Siong, N.K. A Simple Explanation of Partial Least Squares. Draft: 27 April 2013. Available online: https://citeseerx.ist.psu.edu/ viewdoc/download?doi=10.1.1.352.4447\&rep=rep1\&type=pdf (accessed on 7 November 2021).

28. Varmuza, K.; Filzmoser, P. Introduction to Multivariate Statistical Analysis in Chemometrics; CRC Press: Boca Raton, FL, USA, 2016. [CrossRef]

29. Stott, A.E.; Kanna, S.; Mandic, D.P.; Pike, W.T. An online NIPALS algorithm for Partial Least Squares. In Proceedings of the 2017 IEEE International Conference on Acoustics, Speech and Signal Processing (ICASSP), New Orleans, LA, USA, 5-9 March 2017; pp. 4177-4181. [CrossRef]

30. Wodyński, A.; Lasocki, S. Badanie wpływu wstrząsów górniczych na zużycie techniczne budynków murowanych. Przeglad Górniczy 2003, 59, 1-6. 